\title{
Effect of Pre-Sowing Treatments and Fruit Size on Germination of Terminalia arjuna
}

\author{
Khanzad Gul Zazai ${ }^{1 *}$, Narinder Singh Raina ${ }^{2}$ and Sandeep Sehgal ${ }^{2}$ \\ ${ }^{1}$ Division of Forestry Agriculture Faculty of Paktia University Afghanistan \\ ${ }^{2}$ Division of Agroforestry SKUAST-Jammu, Chatha 180009, India \\ *Corresponding author
}

\section{A B S T R A C T}

\section{Keywords}

Presowing treatments,

Fruits size, Germination

$\%$ and Terminalia arjuna

Article Info

Accepted:

12 August 2018

Available Online:

10 September 2018
The experiment was conducted in Division of Agroforestry, Sher-e-kashmir University of Agricultural sciences and Technology of Jammu, Chatha, during the year 2017. Mature fruits were collected from randomly selected four trees and were graded into small (S), medium (M) and large size (L) on the basis of diameter. The fruit subjected to four presowing treatments were sown in polythene bags with potting mixture consisting of soil, sand vermicompost and FYM in $(1: 1: 1: 1)$ ratio. The experiment was laid out in nursery conditions in Factorial CRD with four replications to determine most suitable fruit size and pre-sowing treatment for quality-planting stock and to enhance the germination of the species for the artificial regeneration. In order from the study that large size fruits (L) exhibited all other grades in all seedling growth parameters. The fruits treated with conc. $\mathrm{H}_{2} \mathrm{SO}_{4}$ soaking for 10 minutes $\left(\mathrm{T}_{3}\right)$ and large fruit size $(\mathrm{L})$ indicated significantly maximum germination percentage.

\section{Introduction}

Plants especially trees are an important part of every community. Since the beginning, trees have furnished us with two of life's essentials, food and oxygen. Besides these, they provided additional necessities such as shelter, medicine, architectural, sound barriers, engineering functions and tools. Trees contribute to environment by improving air quality, climate amelioration, conserving water, preserving soil, and supporting wildlife. Medicinal trees play an essential role in health care and they are the major raw materials for both traditional and conventional medicine preparations. In India, medicinal plants are used to prevent different critical diseases and they are the best source to obtain a variety of drugs. The Indian traditional medicine is based on various systems such as Ayurveda, Siddha, Unanai, etc. (Tyler and Premila, 2014).

Terminalia arjuna is one of the multipurpose tree species of Combretaceae family, used for the treatment of cardiovascular diseases. It is a large evergreen tree distributed throughout the greater part of the India; it is seen all around the sub-Himalayan tracts, the Deccan regions, Myanmar and Sri Lanka (Warrier et al., 1994; Anonymous, 1999; Chopra et al., 1958; Kirtikar and Basu, 1989). 
The panicle spikes of small white or yellowish flowers appear from April to July, having the fruits ripen during February to May. The fruits are $2.5-6.5 \mathrm{~cm}$ long and $0.5-1 \mathrm{~cm}$ broad and five to seven wings (Nadkarni, 1976). Leaves are like that of guava leaves, oblong and 4-6 inch long and 2-3 inch wide, glabrous and often in equilateral. There are two glands near the base of the petiole. The margin is crenate with apex at obtuse or sub-acute angle, the base is rounded or cordate, and petioles run for $0.5-1.3 \mathrm{~cm}$. (Padmaa, 2010). Terminalia arjuna, a great medicinal tree and stem bark, leaves and fruits are used in indigenous system of medicine for different ailments.

The bark powder has been found to possess cardio protective properties, anti-ischemic, antioxidant action, hypercholesterolemia effect, fungicidal and antibacterial, antimicrobial, anti-inflammatory Warrier et al., 2014). It is also useful to cure obesity, hypertension and hyperglycemia (Tyler and Premila, 2014). The higher antioxidant potential of stem bark is due to the presence of higher amount of phenolic and flavonoids (Shahriar et al., 2012). These phytochemicals are considered as one of the best heart tonic.

In order to produce quality-planting material of $T$. arjuna the hard seed coat is the major hindrance in achieving good and uniform germination. In such a situation, it is important to standardize its nursery practices to obtain quality-planting stock and to enhance the germination of the species for the artificial regeneration.

\section{Materials and Methods}

Study Site and Fruits collection. The experimental site situated in subtropical, Jammu region of Jammu and Kashmir State, Sher-e-Kashmir University of Agricultural Sciences \& Technology of Jammu, Division of Agroforestry which is located at an altitude
$332 \mathrm{~m}$ above mean sea level with $32^{\circ} 40^{`} \mathrm{~N}$ latitude and $74^{\circ} 58^{\prime} \mathrm{E}$ longitude, annual rainfall ranges from $1000 \mathrm{~mm}$ to $1200 \mathrm{~mm}$. Mature fruits of Terminalia arjuna were collected from randomly selected four trees from the main campus of SKUAST-Jammu, Chatha.

\section{Experimental design and treatments}

There were four treatments in the experiment: $\mathrm{T}_{1}$, soaking fruits in water (at room temperature) for 36 hours; $T_{2}$, soaking fruits in hot water for 6 hours; $\mathrm{T}_{3}$, soaking fruits in conc. H2SO4 for 10 minutes; T4, control - no treatment. The treatments were completely randomized in four replicates. Each treatment had 60 fruits of different size and weight making a total of 300 fruits that were used for the whole treatment. Fruits were sown on 31 July 2017 in polythene bags filled with soil collected form nursery of Division of Agroforestry, Sher-e-kashmir University of Agriculture Sciences and Technology, Jammu. The soil was sandy loam (Rana and Sood, 2012). Media for the experiment was prepared by using soil, sand, (FYM) and vermicompost (VC). The composition for the growing media comprised Soil: Sand: FYM: vermicompost (1: 1: 1: 1). Regular watering was done as per requirement to maintain adequate moisture necessary for germination and seedling growth.

\section{Data collection and analysis}

Germination was recorded daily for 4 weeks until the cease of emerging germinated fruits. Daily germination percentages were summed up to obtain cumulative germination for each treatment. Germination percentage was calculated by dividing the total number of seeds that germinated in each treatment by the number of seeds sown (excluding dead seeds) and multiplied by 100 . 
Germination $(\%)=\frac{\text { Total No. of seed germinated }}{\text { Total No. of seeds sown }} \times 100$

Number of days taken for germination. The number of days taken for initiation of emergence of seedling was recorded in each treatment.

\section{Germinating energy}

Germinating energy (GE) was calculated based on the percentage of the total number of seeds that had germinated when the germination reached its peak.

GE $(\%)=\frac{\text { Number of seeds germinated upto time of peak germination }}{\text { Total number of seed sown }} \times 100$

\section{Survival percentage}

The survival percentage of each treatment was recorded at 90 days after seed sowing. The survival percentage was calculated by using formula as given below:

Survival percentage of seedlings $=\frac{\text { No. of survived seedlings }}{\text { Total no. of seedlings }} \times 100$

The data was analysed using the technique of analysis of variance (ANOVA) in accordance with procedure outlined by Gomez and Gomez (1984). The effect of different treatments was tested at 0.05 level of significance. For percent data on germination, survival percentage, germinative energy, and arcsine transformation was done.

\section{Results and Discussion}

Summary results of pre-sowing treatments for germination percentage, germinative energy, survival percentage and number of days taken for germination of Terminalia arjuna at nursery stage are presented in Table 1 . The maximum germination of $(51.66 \%)$ was observed in the $T_{3}$, which is statistically higher than all remained treatments. The minimum germination $(15.00 \%)$ was observed in the treatment $T_{4} . T_{1}$ and $T_{2}$ were statistically at par each other. The pre-sowing treatments also had significant influence on germinative energy. The maximum germinative energy of (31.66\%) percent was observed in the $\mathrm{T}_{3}$ and minimum germinative energy $(15.00 \%)$ was observed in the treatment $T_{4}$, where $T_{2}$ and $T_{1}$ were the second and third most effective method respectively to enhance the germinative energy. Survival percentage was maximum $(64.75 \%)$ in the $\mathrm{T}_{3}$ which was statistically higher than that of remaining presowing treatments. The minimum survival percentage was recorded in $\mathrm{T}_{4}$. The presowing treatments were statistically significant on number of days for germination, the maximum (17.36 days) number of days for germination were recorded in treatment $T_{1}$, whereas the lowest of (12.50) days) were recorded in treatment $\mathrm{T}_{3}$ (Table 1 ).

The fruit size also had significant influence on germination percentage. The maximum germination of $(42.18 \%)$ was recorded in large fruit size (L) which statistically differed from all remained fruit size, whereas the minimum of $(30.62 \%)$ percent was recorded in medium fruit size (M) which was at par with small fruit size (S) (Table 2). The maximum germinative energy of $(27.18 \%)$ percent was recorded in large fruit size (L), whereas the minimum of 19.37 percent was recorded in medium fruit size (M). The highest survival percentage of (68.04\%) was observed in large fruit size (L) whereas, the lowest survival percentage $(48.54 \%)$ was observed in medium fruit size (M). Fruit size had no significant effect on number of days for germination in the present experiment; it was at par each other's where the highest value was observed in $T_{1}$ and minimum in $\mathrm{T}_{3}$ (Table 2).

The interaction of pre-sowing treatments $x$ fruit size was also significant with respect to germination percentage $(80.00 \%)$ was highest in $\left(\mathrm{T}_{3} \times \mathrm{L}\right)$, germinative energy $(50.00 \%)$ was 
highest in $\left(\mathrm{T}_{3} \times \mathrm{L}\right)$ and survival percentage $(93.22 \%)$ was also highest in (T3 $x$ L), whereas the interaction of pre-sowing treatments $x$ fruits size was non-significant for number of days for germination.

As per the results, all the studied parameters viz. germination percentage, germinative energy, survival percent and number of day taken for germination were significantly influenced by the pre-sowing treatments. All these parameters were best in $\mathrm{T}_{3}$ except for number of days for germination. Higher values for these parameters were obtained in pre-sowing treatment $T_{3}$. It might be due to softening of fruit coat as well as the seed coat, which made the passage of moisture into the cotyledons. These results are in conformation with (Jayant, kumar and kumar, 2000) who reported 91 per cent germination in Ficus auriculata seeds treated with concentrated $\mathrm{H}_{2} \mathrm{SO}_{4}$ for 7 minutes compared to 67 percent in control. Singh et al., (2004) studied the effects of pre-sowing treatment on seed germination and seedling growth of Zizyphus mauritiana, and the result revealed that the highest seed germination (54.22\%). Singh and
Arunachalam (2002) reported the effect of various pre-sowing treatments viz., mechanical scarification and $\mathrm{H}_{2} \mathrm{SO}_{4}$ on seed germination of five leguminous trees species, the seeds treated with $\mathrm{H}_{2} \mathrm{SO}_{4}$ gave best germination. Similar observation was made by Jinnui et al., (2008) in Indigofera pseudotinctoria, wherein treated with $98 \%$ $\mathrm{H}_{2} \mathrm{SO}_{4}$ for 20 minutes resulted into highest value of seed germination rate, germination energy and vigor index. Similar results were also reported that seed germination percentage for Acacia senegal seeds that were treated with $\mathrm{H}_{2} \mathrm{SO}_{4}$ for 20 minutes (Marimuthu et al., 2001).

Germination energy also differs significantly due to pre-sowing treatments. Highest germination energy was recorded in $\mathrm{T}_{3}$ $(31.66 \%)$. The results are in harmony with those reported for Ribes orientale (Sharma et al., 2005), Acacia auriculiformis (Marunda, 1990), Indigofera pseudotinctoria (Jinnui et al., 2008), Grewia optiva (Singh et al., 1997) and Terminalia bellerica (Chakraborty et al., 1992) (Fig. 1 and 2).

Table 1: Summary of different pre-sowing treatments methods effects on the germination percentage, germinative energy, survival percentage and number of days taken for germination of Terminalia arjuna at nursery stages.

\begin{tabular}{|lcccc|}
\hline & $\begin{array}{c}\text { Germination } \\
\text { Percentage }\end{array}$ & $\begin{array}{c}\text { Germinative } \\
\text { Energy }\end{array}$ & $\begin{array}{c}\text { Survival } \\
\text { Percentage }\end{array}$ & $\begin{array}{c}\text { Number of days taken for } \\
\text { germination }\end{array}$ \\
\hline Treatments & & & & 17.36 \\
\hline $\mathrm{T}_{1}$ & 33.75 & 18.75 & 53.26 & $(46.80)^{* *}$ \\
$\mathrm{~T}_{2}$ & $(34.72)^{* *}$ & $(25.41)^{* *}$ & 64.58 & 13.33 \\
$\mathrm{~T}_{3}$ & 38.33 & 23.33 & $(55.27)^{* *}$ & 12.50 \\
$\mathrm{~T}_{4}$ & $(38.16)^{* *}$ & $(28.66)^{* *}$ & 64.75 & 15.50 \\
& 51.66 & 31.66 & $(55.36)^{* *}$ & \\
CD 0.05 & $(46.13)^{* *}$ & $(33.75)^{* *}$ & 43.75 & 2.56 \\
\pm SE (m) & 15.00 & 15.00 & $(39.11)^{* *}$ & 0.89 \\
\hline
\end{tabular}

**Figures in parenthesis are transformed (angular) values

Note: $T_{1}$ - soaking fruit in water (at room temperature) for 36 hours; $T_{2}$ - soaking fruit in hot water for 6 hours

$\mathrm{T}_{3}$ - soaking fruit in conc. $\mathrm{H}_{2} \mathrm{SO}_{4}$ for 10 minutes and $\mathrm{T}_{4}$ - Control - no treatment 


\section{Factorial CRD design was used for this experiment}

\begin{tabular}{|c|c|c|c|}
\hline Category & 100-Fruits weight(g) & $\begin{array}{c}\text { Fruits diameter mean } \\
(\mathrm{cm})\end{array}$ & $\begin{array}{c}\text { Fruits diameter range } \\
(\mathrm{cm})\end{array}$ \\
\hline Small & 170.00 & 1.90 & $1.6<2.2 \mathrm{~cm}$ \\
\hline Medium & 270.00 & 2.66 & $2.2<2.9 \mathrm{~cm}$ \\
\hline Large & 490.00 & 3.18 & $2.9<4.3 \mathrm{~cm}$ \\
\hline
\end{tabular}

Table 2: Summary of different fruits size effects on the germination percentage, germinative energy, survival percentage and number of days taken for germination of Terminalia arjuna at nursery stages.

\begin{tabular}{lcccc|}
\hline & $\begin{array}{c}\text { Germination } \\
\text { Percentage }\end{array}$ & $\begin{array}{c}\text { Germinative } \\
\text { Energy }\end{array}$ & $\begin{array}{c}\text { Survival } \\
\text { Percentage }\end{array}$ & $\begin{array}{c}\text { Number of days taken for } \\
\text { germination }\end{array}$ \\
\hline Fruits size & & & & \\
\hline Small (S) & 31.25 & 20.00 & 53.17 & 14.44 \\
& $(33.60)^{* *}$ & $(26.55)^{* *}$ & $(46.69)^{* *}$ & \\
Medium (M) & 30.62 & 19.37 & 48.54 & 14.94 \\
& $(32.69)^{* *}$ & $(25.64)^{* *}$ & $(43.50)^{* *}$ & \\
Large (L) & 42.18 & 27.18 & 68.04 & 14.65 \\
& $(39.47)^{* *}$ & $(30.18)^{* *}$ & $(57.21)^{* *}$ & \\
CD 0.05 & 5.46 & 3.63 & & \\
\pm SE (m) & 1.90 & 1.26 & 3.15 & N.S. \\
\hline
\end{tabular}

${ }^{* * *}$ Figures in parenthesis are transformed (angular) values

Fig.1 Effect of pre-sowing treatments methods on the germination percentage, germinative energy and survival, percentage of Terminalia arjuna. $\mathrm{T}_{1}$ - soaking fruit in water (at room temperature) for 36 hours; $T_{2}$ - soaking fruit in hot water for 6 hours; $T_{3}$ - soaking fruit in conc.

$\mathrm{H}_{2} \mathrm{SO}_{4}$ for 10 minutes and $\mathrm{T}_{4}$ - Control - no treatment

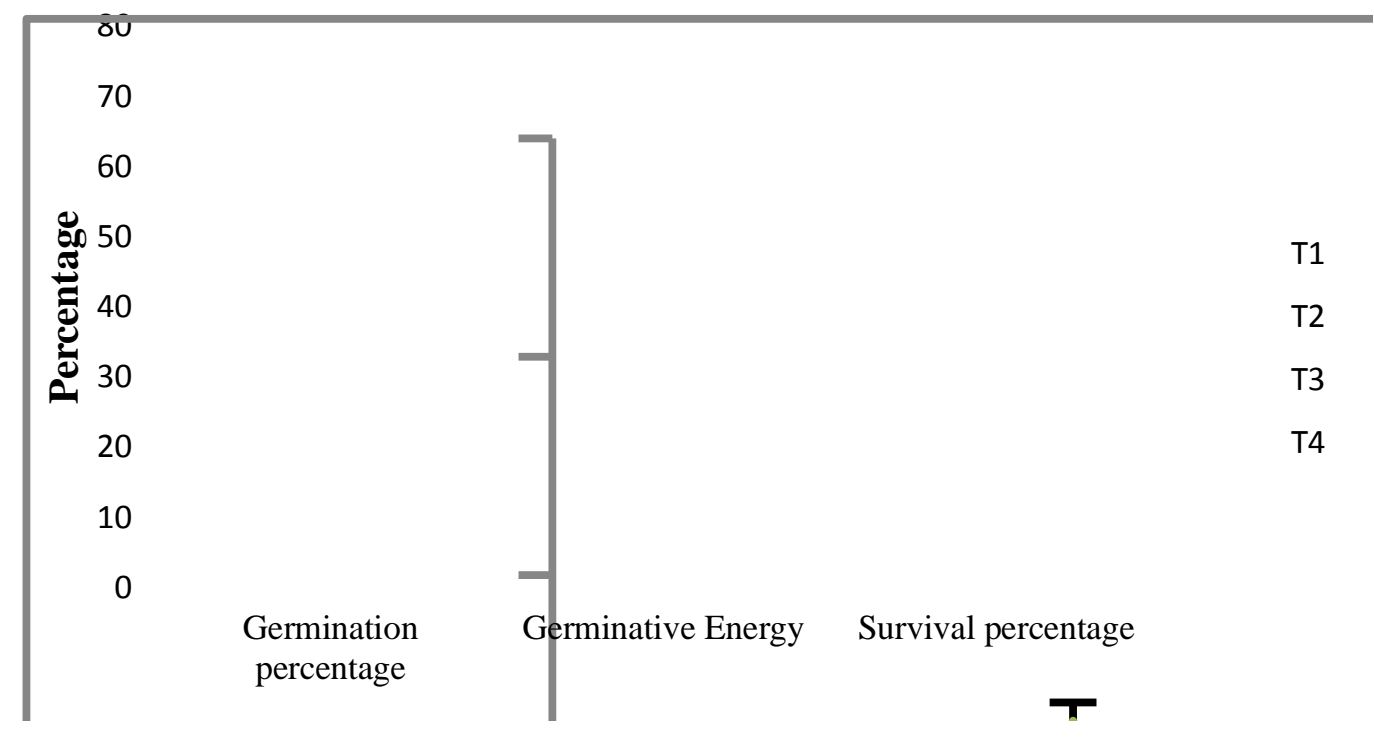


Fig.2 Effect of fruits size on the germination, germinative energy and survival, percentage of Terminalia arjuna

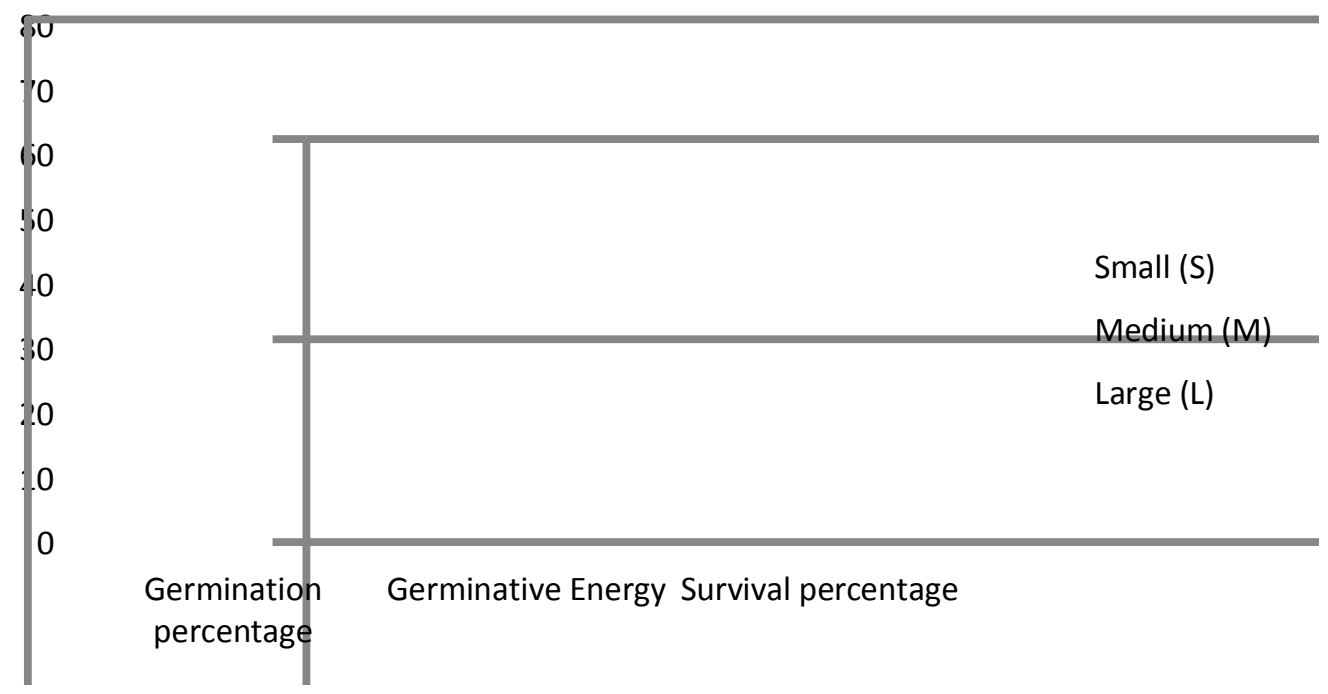

The pre-sowing treatments significantly influenced the survival percent. The survival percentage was maximum $(64.75 \%)$ in the $\mathrm{T}_{3}$ (soaking fruit in conc. $\mathrm{H}_{2} \mathrm{SO}_{4}$ for 10 minutes) which was statistically higher than that of remaining pre-sowing treatments. Similar result was reported by Gupta (2002) that $\mathrm{H}_{2} \mathrm{SO}_{4}$ treatment up to $(20 \%)$ increased the germination rate $(84-86 \%)$ and resulted in better seedling survival (80\%) in Asparagus racemosus when sown in field. Also (Agbogidi et al., 2007) demonstrated that acid pre-treatment of Dacryodes edulis has a highly significant effect of improving seed viability and enhances seedling emergence and seedling growth.

Weight and diameter of 100 fruits of Terminalia arjuna varied significantly among different fruit size categories. Maximum fruit weight and diameter was recorded in large fruit size (L) and minimum in small fruit size (S). Possible reasons for the difference in the seed weight may be ascertained due to seed size variation. The seed size usually reflects the comparative nutrient pool and energy of a seed, which affects the future growth and development. The bigger seed size and more seed weight contain more amount of reserve food material in contrast to smaller seed (Athaya, 1985). Similar results have also been reported for Emblica officinalis, Syzygium cumini, Zizyphus mauritiana and Tamarindus indica (Parameswari and Srimathi, 2009) and Pongamia pinnata (Manonmani et al., 1996).

In the present study, there were significant differences in all the parameters viz. germination percentage, germinative energy, survival percentage were recorded in large fruit size except for number of days for germination. It could be as a result of storage of more food substances in its seed, which might have influenced quicker metabolic activities for faster germination, and growth of seedlings. The results from the study showed that fruit size significantly influenced the germination percentage. Generally, large seed germinate faster and more completely than smaller ones due to more endosperm nutrient pool. The variation among the seeds size categories with respect to germination percentage have been earlier reported in Sapindus emerginatus (Venkatesh and Nagarajaiah, 2010; Suresha et al., 2007); Jatropha curcas (Singh and Saxena, 2009). 
The maximum germinative energy was recorded in large fruit size (L) (Table 2). The results are in harmony with the findings reported in Albizia lebbek (Kumar et al., 2001), Acacia senegal (Harsh et al., 2004) and Eucalyptus citriodora (Aguiar and Nakane, 1983).

The effect of interaction between pre-sowing treatments and fruit size was significant on germination percentage, germinative energy, and survival percentage except for number days for germination. Higher values of these parameters were recorded in treatments combination were recorded in treatments combination number of days taken for germination.

In general, there was an increase in germinability parameters as a result of presowing treatments. However, large sized fruits (L) soaked in conc. $\mathrm{H}_{2} \mathrm{SO}_{4}$ for 10 minutes $\left(\mathrm{T}_{3}\right)$ results in maximum germination and growth of the seedlings.

\section{References}

Agbogidi, O. M., Bosah, B. O. and Eshegbeyi, O. F. 2007. Effects of acid pre-treatment on the germination and seedling growth of African pear Dacryodes edulis Don. G. Lam. H.J.). International J. Agricultural Research, 2(11): 952-958.

Aguiar, I. B. and Nakane, J. T. 1983. Seed size of Eucalyptus citriodora: influence on germination and vigour. Brasil Florestalz, 13(53): 25-28.

Anonymous, 1999. The Ayurvedic pharmacopoeia of India. Part 1 Ministry of health and family welfare, New Delhi.

Athaya, C. D. 1985. Ecological studied of some forest tree seed, seed morphology. Indian Journal of Forestry, 8(1): 33-36.

Chakraborty, A. K., Pandey, O. N. and Bhardwaj, S. D. 1992. Presowing treatment on seeds of Terminalia bellirica. Journal of Research, Birsa Agricultural University, 4(1): 95-98.

Chopra, R. N., Chopra. I. C., Handa, K. L. and Kapur, L. D. 1958. Chopra's indigenous drugs of India. Dhur and Sons private Ltd., Calcutta.

Gomeze, K. A., Gomeze, A. A. 1984. Statistical procedure for Agricultural Research. John Wlley and Sons, New York, U.S.A.

Gupta, S. C. 2002. Seed dormancy studies in some Ocimum species and its control through chemical treatment. J. Med. Arom. Plant.Sci, 24: 957-960.

Harsh, L. N., Bohra, M. D., Khan, H. A. and Tewari, J. C. 2004. Effect of drought on seed quality and germination of Acacia Senegal Willd. Indian Journal of Forestry, 27 (2): 181-185.

Jayant, K. and Kumar, J. P. 2000, Standardization of sexual and asexual propagation techniques for some wild fruits sub Himalayan region. Indian for 126(7): 870-873.

Jinnui, Y. U, Lixing, H., Minge, B. Hua, Q. and Tanjun, Z. 2008. Effect of different treatments on seed germination of Indigofera pseudotinctoria. Journal of Zhejiang Forestry Science and Technology, 25(5): 57-60.

Kirtikar, K. R. and Basu, B. D.1989. Indian medicinal plants. L. M Basu publication, Allahabad.

Kumar, M., Bhardwaj, S. D. and Panwar P. 2001. Effect of pod and seed size on germination parameters of Albizia lebbek. Indian Journal of Forestry, 24 (4): 496499.

Manonmani, V, Vanangamudi, K. and Rai, R. S. V. 1996. Effect of seed size on seed germination and vigour in Pongamia pinnata. Journal of Tropical Forest Science, 9(1): 1-5.

Marimuthu R., Swarnapriya, R., Vairavan, K. and Dhanakodi, C. V. 2001. Presowing treatment with acid strongly influences germination and seedling growth of gum arabic. Agroforestry Today, 13(1/2): 2829. 
Marunda, C. T. 1990. Effects of seed pretreatments on the development of Acacia auriculiformis and Acacia holosericea seedlings. ACIAR Proceedings Series, (28): 33-36.

Nadkarni, A. K. 1976. Indian Materia Medica. 1st Edn., Popular Prakashan, Mumbai, India.

Padmaa, Paarakh. 2010. Terminalia arjuna (Roxb) Wt. and Arn: A Review. International Journal of pharmacology, 6(5): 515-534.

Parameswari, K. and Srimath, I. P. 2009. Seed size influencing seed quality in few tree crops. International Journal of Plant Sciences, 4(1):208-211.

Rana, R. S. and Sood, K. K. 2012. Effect of cutting diameter and hormonal application on the propagation of Ficus roxburghii Wall. through branch cuttings. Analysis of forest research, 55(1): 69-84.

Shahriar, M., Akhter, S., Hossain, M. I., Haque, M. A. and Bhuiyan M. A. 2012. Evaluation of in vitro antioxidant activity of bark extracts of Terminalia arjuna. $J$ Med Plants, 6:5286-98.

Sharma, S., Kumar, S., Thakur, K. S., Negi, P. S. 2005. Study on effect of pre-sowing treatments on germination of Ribes orientale Desf. seeds. Indian Forester, 131(5): 667-672.

Singh, C., Kumar, V., and Sharma, N. K. 1997. Germination behaviour of Grewia optiva (Drumm.) seeds under different presowing treatments. Van Vigyan, 35 (3/4): 132-136.

Singh, D. K., Singh, B. and Sen, S. K. 2004. Role of pre-sowing seed treatment with different chemicals and seed sizes on the germination behavior and seedling growth of (ber) Ziziphus mauritiana Lam. Environment and Ecology, 22(2): 439442.

Singh, N. and Saxena, A. K. 2009. Seed size variation and its effect on germination and seedling growth of Jatropha curcas L. Indian Forester, 135 (8): 1135-1142.

Singh, N. D. and Arunachalam, A. 2002. Effect of pre-sowing treatments and seed size on germination in five leguminous tree species. Range management and Agroforestry, 23 (2): 139-143.

Suresha, N. L., Balachandra, H. C. and Shivanna, H. 2007. Effect of seed size on germination viability and seedling biomass in Sapindus emerginatus (Linn). Karnataka Journal of Agricultural Sciences, 20(2): 326-327.

Tyler VM, Premila, M. S. 2014. Ayurvedic Herbs: A Clinical Guide to the Healing Plants of Traditional Indian Medicine, 13, Number 8, pp. 841-842.

Venkatesh, L. and Nagarajaiah, C. 2010. Effect of seed size on germination, viability and seedling biomass in Sapindus emerginatus Linn. Environment and Ecology, 28(1): 25-27.

Warrier, P. K., Nambair, V. P. K and Ramankutti, C. 1994. Indian medicinal plants. A compendium of 500 species. Vol. 1, Oriennt Longman Pvt. Ltd., Madras, India.

Warrier, P. K., Nambiar, V.P. and Ramankutty, C. 2014. Indian Medicinal Plants: A Compendium of 500 Species, Vol. 5. Available from: http://books.google.co.in/ books?id $=\mathrm{X} 2 \mathrm{yNflOPbrgC}$ and $\mathrm{q}=$ terminalia + arjuna\# $\mathrm{v}=$ snippet and $\mathrm{q}=$ terminalia\% 20arjuna and $\mathrm{f}=$ false.

\section{How to cite this article:}

Khanzad Gul Zazai, Narinder Singh Raina and Sandeep Sehgal. 2018. Effect of Pre-Sowing Treatments and Fruit Size on Germination of Terminalia arjuna. Int.J.Curr.Microbiol.App.Sci. 7(09): 1926-1933. doi: https://doi.org/10.20546/ijcmas.2018.709.234 